\title{
Evaluation of methods used to determine realized energy savings
}

\author{
Piet G.M. Boonekamp* \\ ECN-Policy Studies unit, P.O. Box 1, Petten 1755 ZG, The Netherlands
}

Available online 8 November 2005

\begin{abstract}
Most methods to determine realized total energy savings at national or sectoral level make choices, or neglect problems, which hamper the calculation of sound and useful energy-saving figures. Issues are the choice of the right aggregation level, the appropriate variables to construct a reference energy consumption trend, the energy quantities to be applied and interaction between various effects. Uncertainty margins for results lack in most presentations as well. This paper presents six methods, illustrates the adverse effects of certain choices and problems, and investigates how these methods deal with them. The methods are scored with respect to the issues mentioned above. Finally, a number of improvements are suggested, among which the use of final energy demand expressed in primary energy units, and bottom-up analyses at the level of real saving options. The last option is the more important, as it could provide top-down evaluation results (total savings from decomposition) as well as bottom-up policy monitoring results, both being crucial to new European energysaving policy.
\end{abstract}

(C) 2005 Elsevier Ltd. All rights reserved.

Keywords: Evaluation; Energy savings; Methods

\section{Introduction and problem formulation}

Energy savings represent energy that is not used; therefore it cannot be measured directly, except in some cases, such as a straightforward energy conversion process where savings are calculated from improvement of the ratio between measured output and input. But in most practical cases, e.g. heating a dwelling or driving a car, the output or 'achievement' is difficult to define, let alone to be measured. Just measuring the change in energy input is often not enough because the achievement could have changed too. At the level of total energy consumption of sectors or countries things get even more complicated, as will be illustrated later. In all cases the determination of realized savings boils down to answering the question: what would energy consumption have been without the saving activities, keeping the actual achievement the same? Or, as shown in Fig. 1 in a dynamic fashion, what is the reference consumption trend that, compared with the actual energy consumption trend, shows energy savings realized?

\footnotetext{
*Tel.: + 31224564432 ; fax: + 31224563883 .

E-mail address: boonekamp@ecn.nl.
}

Various methods, ranging from simple indicators to sophisticated decomposition methods (see Section 2), have been developed to answer this question. However, most methods make choices, or meet calculation problems, that lead to less valuable results for realized energy savings. A first and rather fundamental issue regards the choice of the reference system to be applied in determining energy savings. For instance, in case of replacing an old refrigerator with the most efficient new type, the chosen reference system can be the old type, the average type in base year or in current year, the type with the lowest efficiency that is currently sold in the shop, etc. Depending on the choices made, different saving figures are found. This problem gets more complicated if savings have to be determined over a longer period. Then the question arises how to calculate savings when the reference system changes. No choices on dedicated systems have to be made at the aggregated level, for instance, sectoral energy use. But here a similar problem arises with respect to aggregated reference energy consumption. This regards the choice of the appropriate variable to construct reference energy consumption. For instance, in the sector Services the reference trend for electricity consumption can be related to either number of employees or total floor area. Different 


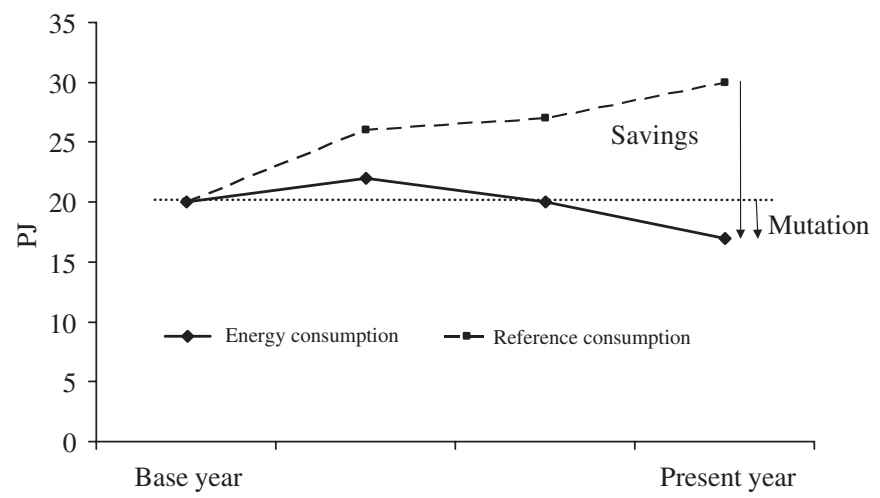

Fig. 1. Actual energy consumption, reference consumption and resulting energy savings.

saving figures will be found, depending on the choice made. In some cases the problem could be mitigated, by executing the analysis at a lower aggregation level. Part of reference electricity use (for lighting) can be coupled to the trend for floor area and other electricity use, for office equipment, to the number of employees. Now the total saving figure found may be 'better' compared to using either floor area or number of employees only. However, this asserts that the amount of savings found depends on the chosen level of aggregation in the analysis. Thus questions about the appropriate level of aggregation arise. This choice not only regards the energy users, but energy use itself as well. Some analysts discern use of fuel and use of electricity in their analysis, while others work with total energy consumption. Another problem is how to cope with interaction between two saving effects. An example, at the aggregation level of home heating, constitutes savings owing to insulation and savings owing to more efficient boilers. Combined savings are less than the sum of savings of the two separately analyzed options. At a higher level of analysis the same applies for savings on final electricity consumption and higher conversion efficiency of power plants. A similar problem regards interaction between saving-effect and other effects, such as growth in energy using activities. For instance, if industrial production increases faster, more new energy systems are needed, thus speeding up electricity savings owing to efficient electric motors. Finally, the chosen quantities to value energy consumption differ. Sometimes total energy consumption is set equal to the sum of energy content of all energy carriers, e.g. in Howarth and Schipper (1991), Fisher-Vanden et al. (2002) or IEA (2004). But some energy carriers have by nature higher end-use efficiency than other carriers, e.g. electricity versus fuels. A shift from fuel to electricity consumption could show up as energy savings in the analysis. The actual effect on total energy supply constitutes higher input though, as the production of electricity causes substantial conversion losses. Using the alternative quantity "primary energy consumption' may avoid this misinterpretation of energysaving trends.
This paper will show that figures on realized energy savings depend strongly on choices made, and on (not) coping with calculation problems. Various calculation methods are compared as to the choices made and the extent they can deal with the problems cited. The focus is on methods to determine energy savings at sectoral or national level. These include new methods: a variant on decomposition analysis (Boonekamp et al., 2004), reconstructed energy balances (Boonekamp, 2004) and bottomup simulation of household energy use (Boonekamp, 1997). It will be shown that these new methods could contribute to solving calculation problems. Even so, in practice all methods can only approximate 'real' energy savings. Therefore attention is paid to treatment of uncertainty in the results provided by various methods.

It must be stressed that this paper regards total realized energy savings, and not the contribution of policy measures or saving programmes most evaluations focus on. The analysis regards historical savings, but most issues presented here are of relevance for calculation of future energy savings in scenario studies. Although cases often regard the Netherlands, reasoning and outcome of analysis are valid for all developed countries. It does not cover problems of comparing country efficiency trends, as highlighted in Phylipsen et al. (1998). Finally, this overview may contribute to the debate on top-down versus bottom-up monitoring for the new EU-directive on energy savings in EU-countries (Bowie and Malvik, 2005).

Chapter 2 provides for a brief overview of generally applied, or new, methods. In Chapter 3 choices and problems in determining savings are described. Showing effects on saving results underlines the relevance of the issues. In Chapter 4 various methods are compared as to their choices and their coping with calculation problems. Chapter 5 presents features of an optimal approach and how various methods fit in. Meeting the evaluation demands of the new EU-directive is discussed too. Conclusions and observations follow in Chapter 6.

\section{Overview of methods to determine energy savings}

\subsection{General concept of determining energy savings}

Before methods and their properties are described, some clarification is given on the connection between socioeconomic activities and energy consumption at different levels of aggregation, and how the methods fit in. At every aggregation level it is possible to define energy-using systems, ranging from a simple light bulb in an office to the national economy. In Table 1 examples of energy using systems are given, classified according to the aggregation levels micro, meso or macro. Input of these systems is by definition energy; output is much more diverse and often difficult to define. Therefore, the general term 'achievement' has already been introduced in Section 1. In literature 'energy services' is mentioned as well, but it does not cover all achievements shown in Table 1. Generally, 
Table 1

Energy-using systems at different aggregation levels, achievements and factors affecting energy consumption

\begin{tabular}{|c|c|c|c|c|}
\hline Level & System & Achievement & Energy savings & Structure \\
\hline \multicolumn{5}{|l|}{ Micro } \\
\hline A & Bulb & Lumen & CFL-kWh & $\mathrm{x}$ \\
\hline B & Engine & Horsepower & Diesel & $\mathrm{x}$ \\
\hline $\mathrm{C}$ & Power station & $\mathrm{kWh}$ & Combined cycle & $\mathrm{x}$ \\
\hline \multicolumn{5}{|l|}{ Meso } \\
\hline A & Office & Lighted space & Daylight switch & Occupation rate \\
\hline B & Car & $\mathrm{Km}$ driven & Driving style & Weight, airco \\
\hline $\mathrm{C}$ & Electr.production & $\mathrm{kWh}$ & Scheduling & Fuel mix \\
\hline \multicolumn{5}{|l|}{ Macro } \\
\hline A & Services & Value Added & $\mathrm{X}$ & Subsector shifts \\
\hline $\mathrm{B}$ & Transport & $\mathrm{Pkm}+\mathrm{tkm}$ & $\mathrm{X}$ & Modal shift \\
\hline \multirow[t]{2}{*}{$\mathrm{C}$} & Energy supply & PJ per fuel & $\mathrm{X}$ & Import/export \\
\hline & Economy/society & GDP & Total savings & Total structure \\
\hline
\end{tabular}

'energy services' is not applied in cases such as energetic outputs of conversion processes or achievements in economic terms (value added or GDP).

At the micro-level one finds stand-alone energy-using systems, where achievements can be defined rather easily. Owing to straightforward relations between energy input and achievement it is rather easy to define energy savings. For instance, if a light bulb is replaced with a more efficient CFL, providing the same amount of light (measured in lumen), savings equal the decrease in electricity used. Car engines on petrol can be replaced with more efficient diesel engines (providing the same amount of horsepower) and conventional gas fuelled power plants can be replaced with very efficient combined cycle units.

At the meso-level energy-using systems are composed of a (great) number of 'micro' systems. For instance, the system 'office' encompasses not only lighting devices, but boilers for space heating and air-conditioning for cooling as well. Achievements generally can be defined in physical terms (e.g. $\mathrm{m}^{2}$ of offices with prescribed lighting levels). Energy savings at meso-level not only comprise all related savings at micro-level, but some specific saving options at this level too. Examples are daylight-dependent switching of lights in offices and, for electricity production, an optimal scheduling of power plants (to save fuels). Energy savings owing to behaviour, such as fuel-saving driving style of car-drivers, are often found at the meso-level. Total energy consumption at meso-level is not only the result of savings mentioned, but is influenced by other so-called structural factors as well. For offices a higher occupation rate generally increases electricity use for lighting, offsetting the decrease owing to savings. For electricity production a change in fuel mix may either strengthen or offset fuel savings.

At the macro-level the 'system' is of an abstract nature, such as industrial production or 'households'. In that case achievement has to be defined in non-material quantities, such as value added for Services. Energy savings at this macro-level are the aggregate of meso-level savings that match. Total energy consumption at this level is also influenced by various structure-effects (see Table 1), but mostly by growth in activities.

At the highest aggregation level, the energy-using system regards the socio-economic system of a country. Generally, achievement is defined here in terms of GDP. Total energy consumption is the result of all savings at lower aggregation levels, all structure effects and growth of GDP.

The methods described here focus on calculation of total energy savings, generally starting on total energy consumption. As can be seen from Table 1, it is not possible to extract total savings from overall energy trend because many growth and structure-effects influence total energy consumption too. Therefore, all methods apply a lower aggregation level in the analysis, sometimes up to the micro-level. The analysis of energy consumption trends at this lower level can take hold of growth- and structureeffects down from the national level (see examples in Table 1), thus enabling calculation of energy savings. In the following, it is described how various methods deal with separating these growth and structure-effects from saving-effects. Actually, this boils down to constructing reference energy consumption trends, from which energy savings follow (see Fig. 1).

The ratio between achievement in monetary quantities and energy use is called 'energy-intensity', expressed in $\mathrm{MJ} /$ Euro. For achievements in physical quantities the ratio is called 'specific energy use'. However, in conformity with many references, here the term energy-intensity is applied in all cases.

\subsection{Methods for determining energy savings at sectoral or national level}

Table 2 presents six methods, currently practised to determine energy savings at national or sectoral level, and 
Table 2

Evaluated calculation methods on energy savings at sectoral or national level

\begin{tabular}{ll}
\hline Method & Scope \\
\hline ODEX (aggregated saving) & EU-countries, total end-use \\
indicator & savings \\
Frozen technology & Various cases, all saving options \\
Decomposition analysis & Various countries and sectors \\
PME-decomposition & Netherlands, main sectors \\
Reconstructed energy balances & Netherlands, statistical sectors \\
Energy trend simulation & Netherlands, households \\
\hline
\end{tabular}

some information on the scope of application. More about properties of these methods will be said in Chapter 4 .

Energy-indicators provide information on efficiency trends for (small) parts of total energy consumption only, e.g. litres of petrol per km driven by car. A number of these indicators can be combined into an aggregated savings indicator, weighting each indicator-trend with the fraction the energy application has in total energy consumption. An example of such an aggregated savings indicator is the $O D E X$-indicator on energy efficiency for EU-countries, described in Odyssee (2003) and Lapillonne et al. (2004). The ODEX-indicator presently consists of 26 separate indicators valid for the end-use sectors industry, households and transportation.

The method frozen technology can be characterized as 'bottom-up' because it regards changes at the level of energy systems and saving options. Total reference energy consumption in a chosen year is determined by means of replacing every actual efficiency value with the base year value. The difference with actual total energy consumption is equal to realized savings. The method demands a detailed description of the total energy system, and related socio-economic factors, where every technology has its place. This method is applied for the Netherlands, using the Icarus-database of energy-saving options, and for Europe, using the European version Genesis, described in Alsema and Nieuwlaar (2001) and Blok (2001).

Decomposition analysis is a 'top-down' method where the analysis generally sets out from total energy consumption and GDP. The change in total energy consumption over time is decomposed into a volume-effect (GDP-growth), a structure-effect (structural changes in the economy) and an energy intensity effect. The intensity-effect, i.e. the decreased intensity, is often referred to as "energy efficiency' gain. In partial (Laspeyres) decomposition a residual term, due to interaction between the effects mentioned, is found. More sophisticated 'complete' methods eliminate the residual term, distributing it to the three effects. An overview of (complete) decomposition algorithms is presented in Ang (1995). Often the structure-effect only regard shifts in the sector contributions to GDP; the intensity-effect represents changes in the ratio $\mathrm{MJ} /$ Euro at the (sub)sector level. Sometimes diverging economic and physical trends in sub-sectors are taken into account as well. Now the intensity-effect, e.g. decreasing $\mathrm{MJ} / \mathrm{kg}$ steel, more closely represent realized energy efficiency, as there is a close relationship between physical developments and energy use (see Schipper et al. (2001)). Other examples of index decomposition analysis are given in Howarth and Schipper (1991), Farla and Blok (1997), Sun (1999) and IEA (2004). Another method, structural decomposition analyses, applies input/output matrices. It enables analysis of changes in final demand for goods and services, and import and export (see Hoen and Mulder (2003)). This decomposition version is not analyzed any further in this paper.

Realized energy savings for the Netherlands are calculated according to the so-called Protocol Monitoring Energy savings (PME), described in (Boonekamp et al., 2004). The PME-decomposition method is a policy oriented mix of partial decomposition analysis and engineering calculations. Energy consumption is divided in final energy demand, conversion in end-use sectors (e.g. cogeneration) and conversion in the energy supply sector. Final demand is split into demand for heat, electricity and feedstocks (see Section 4). For final demand analysis decomposition is applied; for both conversions engineering calculations are deployed.

The MONIT-system for presentation and analysis of national energy trends, described in Boonekamp (2004), applies the concept of reconstructed energy balances. Starting from the base year energy balance, the factors that have changed energy consumption are used to reconstruct step by step the energy balance of the year of interest. This method resembles the PME-decomposition approach with its separate dealing with final demand, cogeneration and energy supply sector. Moreover, the effect of other structural effects, e.g. substitution between energy carriers and energy import/export, are taken into account too (see Fig. 2). A special feature regards expressing all energy consumption figures in primary energy units. For end-use sectors the first eight steps in the reconstruction process regard static primary energy consumption, where each energy carrier is valued according to conversion losses in the base year. Therefore, analysis of end-use trends is not disturbed by energy sector changes. The last six reconstruction steps regard various changes in energy supply. These show the influence of developments in energy supply on primary energy consumption of end-use sectors.

Energy trend simulation is, like frozen technology, a bottom-up method to calculate realized savings in conjunction with other factors. The case to be evaluated regards the household sector in the Netherlands, as described in Boonekamp (1997). Here energy consumption is split into seven energy functions (space hating, food cooling, etc.), each comprising a number of energy systems or appliances. For all systems/appliances a vintage approach is applied to describe the shifting composition of the stock with respect to efficiency. For each fifth year a complete picture of systems and actual energy use is 


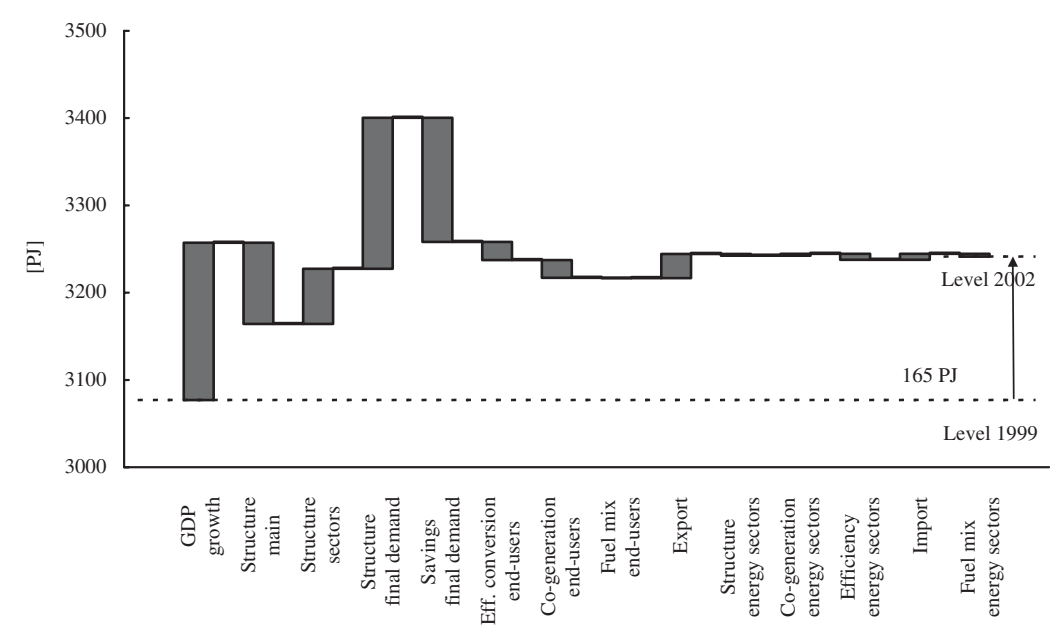

Fig. 2. Decomposition of the change in total energy consumption 1999-2002 for the Netherlands, using the reconstructed energy balances method.

composed, using information from detailed surveys and general statistics. Reference energy consumption is calculated, setting the mix of more or less efficient systems and appliances equal to that in the base year, while growth and structural factors change the amount and utilization of systems and appliances. Comparison with actual energy consumption delivers realized energy savings. A special feature of this method regards simulation of historic energy trends, using a cost/benefit approach, energy prices and policy measures to model decisions to implement saving options. This enables to trace causes for realized savings, as is shown in Boonekamp (2005). At EU-level the MURE-simulation tool is available to determine impacts of different policy measures in EU-countries. Applications regard effects of past policy measures in various end-use sectors, described in the back-casting cases of MURE (2003).

To complete the overview, the regression analysis method has to be mentioned too. However, reported cases in literature generally regard policy-related applications, such as effects of government sponsored savings programmes. Regression analysis attributes the observed decrease in energy use to either the saving programme or to other factors. In Blasnik (1995) an overview is given of applications and methodological issues. One known example of regression analysis, applied for calculating realized energy savings in the Dutch greenhouses sector, is described in RK (2003). Given the different focus, this method is left aside in this paper.

\section{Choices or problems and their adverse effect on energy- saving results}

In this section the choices or problems already mentioned in Section 1 are elucidated (see Table 3). These issues regard either the micro- or macro-level, or show up at both levels (see table). Issues at the micro-level are only
Table 3

Overview of calculation issues relevant at different aggregation levels of analysis

\begin{tabular}{|c|c|c|}
\hline & Micro & Macro \\
\hline Choice of reference system & $\mathrm{R}$ & \\
\hline Choice of variables for reference trend & & $\mathrm{R}$ \\
\hline Shifts in reference system & $\mathrm{R}$ & \\
\hline Choice of aggregation level & & $\mathrm{R}$ \\
\hline Interaction between saving effects & $\mathrm{R}$ & $\mathrm{R}$ \\
\hline Interaction saving effect and other effects & $\mathrm{R}$ & $\mathrm{R}$ \\
\hline Choice of energy quantity to be applied & $\mathrm{R}$ & $\mathrm{R}$ \\
\hline
\end{tabular}

$\mathrm{R}=$ relevant at this aggregation level.

relevant for some calculation methods that regard savings at micro as well as national level (see Section 4).

\subsection{Choice of reference system}

At the micro-level energy savings are accomplished by implementing new, more efficient, systems. Then one has to decide on the reference system, to be used in calculation of energy savings. Take for instance a small industrial CHPunit installed in 1997, as part of the Environmental Action Plan (MAP) of the Dutch distribution companies. The reference system consists of a gas fired boiler and central electricity supply. Given parameters at actual start up of the plan in 1992, the industrial CHP-unit uses $34 \%$ less energy (see Table 4). In 1996 central capacity has been extended with very efficient combined cycle-units. This increased average conversion efficiency to $41.3 \%$ (including transport and distribution losses). Now the same unit saves only $30 \%$. Finally, one could postulate that without CHP very efficient combined cycle-units with at least $54 \%$ efficiency (excluding grid losses) would be in place. This marginal approach results in $21 \%$ savings only. 
Table 4

Energy savings of CHP-units related to choice of reference system

\begin{tabular}{|c|c|c|c|c|}
\hline & \multicolumn{3}{|c|}{ Conversion efficiency } & \multirow[t]{2}{*}{ Savings from CHP (\%) } \\
\hline & Boiler $(\%)$ & Central power $(\%)$ & CHP (\%) & \\
\hline Reference system & & $(*)$ & & \\
\hline Average central, base year & 85 & 38.2 & $35 / 50$ & 34 \\
\hline Average central, 1997 & 85 & 41.3 & $35 / 50$ & 30 \\
\hline Marginal central, 2000 & 85 & 51.0 & $35 / 50$ & 21 \\
\hline
\end{tabular}

(*) including 5\% transmission losses.

Table 5

Total energy savings and choice of scaling variables for reference energy consumption (Dutch Households, yearly average change1990-2000)

\begin{tabular}{|c|c|c|c|}
\hline Scaling variable(s) & Energy use (\%) & Reference use $(\%)$ & Energy savings $(\%)$ \\
\hline Number of inhabitants & +0.9 & +0.6 & -0.2 \\
\hline Number of households & +0.9 & +1.3 & +0.4 \\
\hline Item + surface + appliances & +0.9 & +2.1 & +1.2 \\
\hline All relevant factors & +0.9 & +3.1 & +2.2 \\
\hline
\end{tabular}

\subsection{Choice of variables to construct the reference trend}

At the macro-level it has to be decided how the reference trend for energy consumption (without savings) is determined. A major problem is choice of variable(s) to construct reference energy consumption, i.e. reference or scaling variables. This is illustrated in Table 5 for total primary energy consumption of households in the Netherlands (with electricity use converted to primary energy). Given an actual increase in primary energy consumption of approximately $0.9 \%$ per year, calculated energy savings vary between $-0.2 \%$ and $2.2 \%$. Scaling of reference energy consumption with number of inhabitants provides negative savings because extra energy use due to a faster increase in number of dwellings is not taken account of. Scaling with number of dwellings leads to small savings only, because it omits factors that increase energy use per household, such as larger new dwellings and higher ownership rates for appliances. If these two factors are taken into consideration, again higher savings result. Much more factors are accounted for in a bottom up simulation of household energy use, described in Boonekamp (1997) and updated in Boonekamp (2005). Almost all additional factors contribute to increased energy use per household; given realized energy consumption, energy savings must be higher than resulting from simple analyzes.

Not taking into account relevant structure-effects may even produce negative energy-saving figures. Especially in constructing reference electricity consumption it proves to be difficult to incorporate the scaling variables that account for new electricity applications. Sometimes the reference trend lies below the actual trend. Such cases with negative saving figures have been found in Farla and Blok (1997) and Groot (1996) for electricity trends in Dutch services. Even so, according to programme evaluations (EnergieNed, 1995) some energy savings were realized here.
Table 6

Varying energy savings for shifting reference system (refrigerator example)

\begin{tabular}{llll}
\hline & $\begin{array}{l}\text { New } \\
\text { appliance } \\
(\mathrm{kWh} / \mathrm{y})\end{array}$ & $\begin{array}{l}\text { Reference } \\
\text { appliance } \\
(\mathrm{kWh} / \mathrm{y})\end{array}$ & $\begin{array}{l}\text { Energy } \\
\text { savings } \\
(\mathrm{kWh} / \mathrm{y})\end{array}$ \\
\hline $\begin{array}{l}\text { 1990-1995 } \\
\text { Efficient versus old }\end{array}$ & 350 & 450 & 100 \\
Better versus old & 280 & 450 & 170 \\
$\begin{array}{l}\text { 1995-2000 } \\
\text { Best versus old }\end{array}$ & 200 & 450 & 250 \\
$\begin{array}{l}\text { 2000-2005 } \\
\text { Better versus efficient }\end{array}$ & 280 & 350 & 70 \\
Best versus efficient & 200 & 350 & 150 \\
\hline
\end{tabular}

\subsection{Shifting reference system ${ }^{l}$}

The problem of shifting reference systems regards the micro-level only. When savings have to be determined over longer periods, the reference system probably does not remain the same. Due to technological development or prolonged successful introduction of efficient systems conventional systems may disappear from the market altogether. Then another, more efficient, option becomes the reference system. This mechanism is highlighted in Table 6 for replacement of refrigerators. In the first period 1990-1995 efficient or better versions replace old refrigerators. In the next period saving possibilities increase owing to introduction of even more efficient refrigerators (best). But after disappearance of the old type from stock

\footnotetext{
${ }^{1}$ This differs from earlier presented issue 'choice of reference system' where changes in reference system were a matter of opinion, while here it regards a trend to be dealt with.
} 
of refrigerators (period 2000-2005), the alternatives save less electricity than in earlier periods.

\subsection{Choice of aggregation level}

As already highlighted in the introduction, determination of energy savings could provide better results if energy consumption is split into parts. For every part a separate reference trend is constructed, and the sum of these trends is compared with actual total trend, providing energy savings. In this way different developments for various energy using activities do not influence the saving result. However, the overview for industry in Ang (1995) shows that energy consumption is disaggregated into a limited number of sectors only in most decomposition studies. The reason is that the statistical data often are not easily available at lower aggregation level. The effect of aggregation level on saving results is shown in Fisher-Vanden et al. (2002) where decomposition results are presented for one-digit to fourdigit level, applied in statistical classification of industrial activities. For each case contributions of sectoral shifts and sub-sector energy-intensity changes are presented (see Table 7). Analysis at two-digit instead of one-digit level halves the observed lowering of energy-intensity. Three-digit level results show again 15\% less intensity decrease, but at the four-digit level the intensity decrease stabilizes. It must be concluded that in this (Chinese) case decomposition should be best applied at the three-digit level or lower.

In Seibel (2003) comparable results are found for decomposition of total industrial $\mathrm{CO}_{2}$-emissions in Germany. For 1993-2000 the decrease owing to lower energyintensity is $56 \%$ stronger for 58 sub-sectors than for 12 sectors (51.8 and 33.2 Mton). The sensitivity of results to aggregation level is recognized as a general problem of decomposition in Ang (1995).

\subsection{Interaction between various energy-saving effects}

Sometimes an efficiency increase in one part of the energy system influences energy savings owing to an efficiency measure elsewhere. Then the combined effect may be lower than the sum of effects of both measures apart. An example is the combination of savings on final electricity use of appliances and increased efficiency in electricity production. Table 8 first shows the effect of more efficient appliances on primary energy use, using standard

Table 7

Calculated decomposition effects at various aggregation levels for the Chinese industry, average values 1997-1999

\begin{tabular}{lll}
\hline Statistical aggregation level & Sectoral shift & Energy intensity \\
\hline 1-digit & +0.038 & -0.121 \\
2-digit & -0.024 & -0.059 \\
3-digit & -0.034 & -0.050 \\
4-digit & -0.036 & -0.051 \\
\hline
\end{tabular}

Source: Fisher-Vanden et al. (2002). efficiency values of power plants. Then the separate effect of higher power plant efficiency is calculated. The sum of both proves to be $7 \%$ higher than primary savings in the combined case.

Next to this example at the macro-level, interaction shows up at the micro-level as well, for instance between savings owing to insulation of dwellings and savings owing to high-efficiency boilers for space heating. Results for households in the Netherlands are given in Boonekamp (1997). Here it is shown that boiler savings would have been $35 \%$ higher ( 6.6 versus 4.9 PJ) if savings on space heat use are not taken into account.

\subsection{Interaction between energy-saving effect and other effects}

The amount of energy saved depends on factors that influence growth of energy consumption as well. For instance, if number of dwellings or surface area per dwelling increase, application of high-efficiency boilers saves more fuel. On the other hand, saturation in demand for building materials may decrease industrial energy savings connected to more efficient kilns. In general, this mechanism applies for all shifts in production and consumption activities. The interaction between energy savings and these socio-economic developments (called intensity- and structure/volume-effects in analysis) has been extensively dealt with in many decomposition studies (e.g. Ang (1995), Schipper et al. (2001) and Sun (1999)).

\subsection{Choice of energy quantity to be applied}

At the aggregated level of end-use sectors, different energy quantities can be applied in the analysis, for reference energy consumption as well as actual energy consumption:

- Energy consumption (total energy content);

- Primary energy consumption;

- Final demand, per end-use form.

In Fig. 3 a general overview of the relationship between the three quantities is given.

First, effects of a choice between energy consumption and primary energy consumption are highlighted. The effect on calculated savings is illustrated in Table 9, for a case that resembles energy use in Services in the Netherlands for 1990-2000. The use of gas and electricity has risen because of growth in activities, but this has been partly compensated for by energy savings. Actual energy consumption, being the sum of energy contents for gas and electricity, has increased; total savings of $50 \mathrm{PJ}$ equal $16 \%$ of total energy consumption in 2000. If electricity use is expressed in primary terms, using an average conversion efficiency of $40 \%$, primary energy consumption is found to increase stronger (see last column). Savings in primary terms score $13 \%$ only, due to the increased weight for 
Table 8

Example of interaction-effect between saving options in end-use and energy supply

\begin{tabular}{|c|c|c|c|c|c|}
\hline & \multicolumn{3}{|c|}{ Electricity use appliances } & \multirow{2}{*}{$\begin{array}{l}\text { Power stations } \\
\text { Efficiency }\end{array}$} & \multirow{2}{*}{$\begin{array}{l}\text { Savings (primary) } \\
\text { PJ }\end{array}$} \\
\hline & $\begin{array}{l}\text { Without } \\
\text { PJe }\end{array}$ & Savings & $\begin{array}{l}\text { With } \\
\text { PJe }\end{array}$ & & \\
\hline Efficient appliances & 20 & $20 \%$ & 16 & $40 \%$ & 10.0 \\
\hline Efficient power stations & 20 & $0 \%$ & 20 & $44 \%$ & 4.5 \\
\hline Sum of energy savings & & & & & 14.5 \\
\hline Combined energy savings & 20 & $20 \%$ & 16 & $44 \%$ & 13.6 \\
\hline Overlap & & & & & 0.9 \\
\hline
\end{tabular}

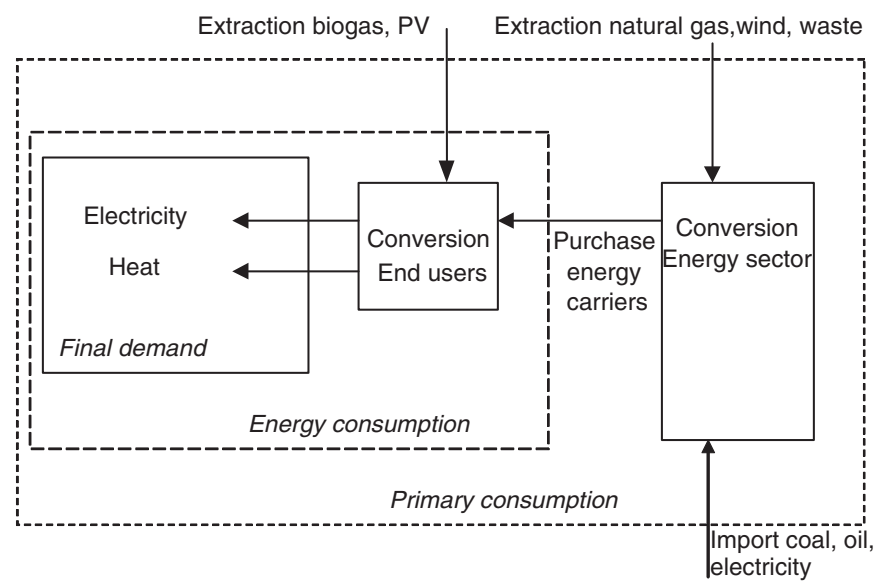

Fig. 3. Connection between final energy demand, energy consumption and primary energy consumption (inputs regard the Netherlands).

electricity showing relatively low savings. These less favourable efficiency trends from applying primary energy are found in Doblin (1998) and Zarnikau (1999) as well.

Substitution between fuels and electricity can influence energy use developments, as electricity causes fewer losses than fuels in end-use applications. For instance, heat can be produced from electricity with an efficiency of $100 \%$, as opposed to the $50-90 \%$ for fuels. Therefore a shift from fuels to electricity shows up as savings, in case total energy consumption is looked at. In Table 9 this is highlighted in the lower part of the table. There it has been supposed that $10 \mathrm{PJ}$ of gas has been replaced with $5 \mathrm{PJ}$ of electricity. With given realized values for 1990 and 2000, and the same growth effects, less gas savings and more electricity savings must have been realized than was calculated earlier. Earlier found savings on energy consumption (16\%) prove to be too high compared to the value of $14 \%$ after correction for substitution. However, the new and old figures for savings in primary energy units $(13 \%)$ are about equal.

The second choice regards the use of the quantity 'final demand' instead of energy consumption. In Fig. 3 it is shown that delivered energy carriers (energy consumption) are converted at the end-users site into the end-use forms heat and electricity (final demand). The amount and composition of energy consumption do not always resemble that of final demand, which ultimately provides for the needs from the socio-economic system. This difference may lead to wrong results for constructed reference energy consumption trends, especially if substantial amounts of electricity and heat are produced in cogeneration units. This is illustrated in Table 10 where gas is used to produce heat in boilers, and a cogeneration unit to produce heat and electricity (see 'actual 1990'). The consumption of (grid delivered) electricity is lower than final use of electricity because of on site production. For 2000 a $50 \%$ higher production level is supposed; in the conventional approach reference consumption of (delivered) gas and electricity increases by $50 \%$ as well. With the chosen actual values for 2000 total savings of $25 \mathrm{PJ}$ result. However, it is more probable that in the reference case final demand for heat and electricity rise by $50 \%$ (see 'Reference 2000-II'). Given unaltered output from cogeneration and boiler efficiency, this results in diverging reference consumption for gas and electricity, compared to the conventional approach. Total energy savings are just 10\% lower but the composition is quite different, causing greater differences in primary energy consumption.

In the preceding example the same growth factor is applied to final heat demand as well as final electricity demand. In reality, electricity demand generally is determined by quite other factors than that for heat. Therefore, final demand should be split into different end-use forms to construct realistic reference trends. This choice has already been dealt with in the paragraph on aggregation.

In the Protocol on calculating energy savings, described in Boonekamp et al. (2004), it is shown that both preferences presented here can be combined. For end-use sectors final demand for heat and electricity, both expressed in primary energy units, are applied throughout the analysis. Finally, it has to be remarked that choices regarding primary energy and final demand are not relevant at the national level. At this level energy consumption consists of primary energy carriers, and the quantity final demand is only valid for end-use sectors.

\section{Treatment of calculation issues in evaluated methods}

Now it is investigated how various methods (see Section 2) make choices, and deal with the calculation problems, as described in the previous section. 
Table 9

Energy savings in relation to energy quantity used in the analysis (example)

\begin{tabular}{|c|c|c|c|c|}
\hline & $\begin{array}{l}\text { Gas } \\
\text { PJ }\end{array}$ & $\begin{array}{l}\text { Electricity } \\
\text { PJe }\end{array}$ & $\begin{array}{l}\text { Energy consumption } \\
\text { PJ }\end{array}$ & $\begin{array}{l}\text { Primary energy } \\
\text { PJ }\end{array}$ \\
\hline Actual energy use 1990 & 200 & 80 & 280 & 400 \\
\hline Growth effect 1990-2000 & 40 & 50 & & \\
\hline Use without savings 2000 & 240 & 130 & & \\
\hline Savings effect 1990-2000 & -40 & -10 & -50 & -65 \\
\hline Actual energy use 2000 & 200 & 120 & 320 & 500 \\
\hline Savings/actual 2000 & $20 \%$ & $8 \%$ & $16 \%$ & $13 \%$ \\
\hline \multicolumn{5}{|l|}{ Substitution variant } \\
\hline Substitution effect & -10 & +5 & & \\
\hline Savings effect corrected & -30 & -15 & -45 & -68 \\
\hline Savings/actual 2000 & $15 \%$ & $13 \%$ & $14 \%$ & $13-14 \%$ \\
\hline
\end{tabular}

Table 10

Energy savings in relation to scaling either energy consumption or final demand for increase in production

\begin{tabular}{|c|c|c|c|c|c|}
\hline & \multicolumn{3}{|c|}{ Energy delivered } & \multicolumn{2}{|c|}{ Final demand } \\
\hline & $\begin{array}{l}\text { Gas } \\
\text { PJ }\end{array}$ & $\begin{array}{l}\text { Electricity } \\
\text { PJe }\end{array}$ & $\begin{array}{l}\text { Total } \\
\text { PJ }\end{array}$ & $\begin{array}{l}\text { Heat } \\
\text { PJth }\end{array}$ & $\begin{array}{l}\text { Electricity } \\
\text { PJe }\end{array}$ \\
\hline Actual 1990 & $100^{\mathrm{a}}$ & 40 & 140 & $67^{\mathrm{a}}$ & $60^{\mathrm{a}}$ \\
\hline Growth 1990-2000 & $+50 \%$ & $+50 \%$ & & & \\
\hline Reference 2000-I & 150 & 60 & 210 & & \\
\hline Actual 2000 & 125 & 60 & 185 & & \\
\hline Energy savings & 25 & $\mathbf{0}$ & 25 & & \\
\hline Growth 1990-2000 & & & & $+50 \%$ & $+50 \%$ \\
\hline Reference 2000-II & 137 & 70 & 207 & 101 & 90 \\
\hline Actual 2000 & 125 & 60 & 185 & & \\
\hline Energy savings & 12 & 10 & 22 & & \\
\hline
\end{tabular}

${ }^{\text {a }}$ Cogeneration: 59 gas used for 30 heat and 20 electricity, boiler: 41 gas used for 37 heat.

\subsection{Choice of reference variables and aggregation level}

Choice of reference variables and choice of aggregation level generally coincide. For instance, in analysis of industrial energy trends, the aggregation level chosen often regards sub-sectors or energy applications, where appropriate physical production quantities are available to construct the reference trend. In Table 11 the various methods are rated as to their handling both issues.

The $O D E X$-indicator is very flexible with respect to aggregation level and choice of reference variables. Even so, a low aggregation level is not always possible because variables at the level of sub-sectors or energy applications are not always available in all EU-countries. The frozen technology method is forced to apply a low aggregation level where changes for energy technologies can be analyzed. At this level energy consumption has to be specified in great detail for each year of analysis. Moreover, all penetration rates of saving options and average efficiency values per application must be known, for base year as well as year of analysis. Decomposition analysis often applies generally available statistical figures, restricting itself to the sectoral level and the use of economic reference variables, as illustrated in IEA (2004). In specific cases, such as Farla and Blok (1997), available physical quantities at sub-sector level are applied as well. PMEdecomposition applies as much as possible physical variables; especially in industry many physical production quantities from Neelis et al. (2004) are used to construct the reference trend. The restrictions, described for decomposition analysis are valid for reconstructed balances as well. But here energy use is split into final demand for heat, electricity and feedstocks, each with their own reference variables. The energy trend simulation method is the only method that does not start from the national level. Like frozen technology it applies the lowest aggregation level where changes for saving options are analyzed. Many variables, at different levels, are needed in the simulation, among which the mix of more or less efficient energy systems or appliances. 
Table 11

Choice of reference variables and aggregation level for various methods

\begin{tabular}{|c|c|c|}
\hline Method & Reference variables & Lowest aggregation level \\
\hline ODEX-indicator & Socio-economic-physical & Application/sub-sectors (end-use sectors) \\
\hline Frozen technology & Not needed (implicit) & Energy system/application + efficient versions \\
\hline Decomposition analysis & Socio-economic & Sector/sub-sector \\
\hline PME-decomposition & Socio-economic-physical & Application + end-use type \\
\hline Reconstructed balances & Socio-economic & Sub-sector + end-use type \\
\hline Energy trend simulation & All relevant variables to describe trends & Energy system/application + efficient versions \\
\hline
\end{tabular}

\subsection{Interaction between energy-saving effects}

At the micro-level interaction between energy-saving effects regards two saving options; at the macro-level it regards interaction between savings on end use and increased electricity supply efficiency. In Table 12 it is shown how the various methods take account of these interactions in the calculation. For methods designed for the macro-level, interaction at the micro-level is not relevant (depicted with ' $\mathrm{X}$ '). This interaction is (in principle) incorporated in total savings, calculated at higher aggregation level.

For the $O D E X$-indicator method the set of separate indicators determines how micro-level interaction is taken care of. For instance the indicator 'energy use for space heating in dwellings' shows the combined saving effect of insulation and high-efficiency boilers. Macro-level interaction, between end-use and supply, is not dealt with because the present ODEX-indicator regards end-use sectors only. Treatment of interaction for frozen technology, micro as well as macro, depends on how this is incorporated in the scheme to calculate energy savings. Macro-level interaction poses no problem in decomposition analysis, provided a separate electricity supply sector is present in the analysis. However, if decomposition analyzes focuses on one enduse sector only, this interaction is not taken account of. The PME-decomposition method calculates savings for three categories: final demand, cogeneration and central electricity production. In conformity with policy evaluation rules in the Netherlands, interactions between the three savings categories are neglected. The reconstructed balances method applies a fixed sequence of 14 analysis steps (see Fig. 2). One of the steps regards calculation of savings on final demand, another one regards conversion efficiency in end-use sectors, and a third step efficiency changes in electricity supply. Savings on final demand are calculated first (with base year conversion efficiency); therefore savings owing to higher efficiency of supply are calculated after dealing with end-use savings (see Section 2). In bottom up energy trend simulation, total savings are the result of penetration of a large number of saving options. The saving effect of every saving option is calculated, introducing saving options one by one in the analysis and keeping track of the cumulative increase in total energy savings (see figure on cumulative total
Table 12

Treatment of interaction between energy saving effects at micro and macro-level for various methods

\begin{tabular}{lll}
\hline Method & Micro & Macro \\
\hline ODEX-indicator & Yes & No \\
Frozen technology & Yes/no & Yes/no \\
Decomposition analysis & $\mathrm{X}$ & Yes/No \\
PME-decomposition & $\mathrm{X}$ & No \\
Reconstructed balances & $\mathrm{X}$ & Yes \\
Energy trend simulation & Yes & Partly \\
\hline
\end{tabular}

$\mathrm{X}=$ not relevant.

savings in Boonekamp (1997)). For two interacting saving options, the calculation sequence defines how combined savings are attributed to both saving options. The average efficiency trend for electricity production constitutes a pseudo-saving option. This enables analysis of savingsinteraction at macro-level, although the efficiency change is not only due to more efficient plants but to fuel substitution as well.

\subsection{Interaction between energy-saving effect and other effects}

Other effects constitute changes in energy consumption related to volume growth and structural changes in the socio-economic system. The resulting size of energy-using activities defines in part the scope for implementation of saving options, and thus energy savings. This interaction can regard micro as well as macro-level analysis (see Table 13). As already shown in Table 12, the micro-level is not relevant for some methods.

Individual indicators that are part of the $O D E X$ indicator take into account some, but not all, interaction effects at the micro-level. For instance, the efficiencyindicator 'average fuel use $/ \mathrm{m}^{2}$ floor area' in dwellings accounts for larger dwellings but not for changes in the type of dwelling. In composing the ODEX-indicator, weighting of individual indicators is performed with fixed values for their fractions in total energy consumption. This way of weighting does not account for structural changes at the macro-level. The frozen technology method focuses on realized energy efficiency improvements for all energy 
Table 13

Treatment of interaction between energy saving effect and other effects at micro and macro level for various methods

\begin{tabular}{lll}
\hline Method & Micro & Macro \\
\hline ODEX-indicator & Partly & No \\
Frozen technology & Yes/no & Yes/no \\
Decomposition analysis & $\mathrm{X}$ & Yes \\
PME-decomposition & $\mathrm{X}$ & Yes \\
Reconstructed balances & $\mathrm{X}$ & Yes \\
Energy trend simulation & Yes & Yes \\
\hline
\end{tabular}

$\mathrm{X}=$ not relevant.

systems (e.g. boilers) in the year of analysis. In combination with the actual numbers and utilization rates for all systems total energy savings result. These numbers and utilization rates depend on volume- and structure-effects with respect to base year (e.g. more boilers due to extra dwellings and central, instead of local, heating). Savingeffects are calculated after processing the volume- and structure-effects. This fixed calculation order defines how interaction is dealt with. Decomposition analysis generally applies algorithms (complete decomposition) that treat interaction between volume, structure and saving effects quite well at the macro-level. Structural changes at lower aggregation level are not observed and become automatically part of the calculated 'efficiency' gain. This mixed saving/structure result incorporates interaction effects at the micro-level. The same reasoning is valid for end-use analysis in PME-decomposition and reconstructed balances methods as well. In the last case the effect of other factors, such as import, export and fuel substitution, on (primary) energy savings is determined separately. For energy trend simulation the same reasoning applies as described in the preceding paragraph. The sequence of introducing volume and structural changes and energy savings in the analysis defines how interaction works out on calculated savings.

\subsection{Chosen energy quantity}

As highlighted earlier, energy consumption can be defined as total energy content of all energy carriers delivered, or can be expressed in primary energy units that account for losses to deliver energy carriers (see Section 3). In the last case a further choice regards static primary, with base year conversion efficiency values, or dynamic primary, with efficiency values in the year of analysis. Delivered energy carriers to end-use sectors are transformed into heat, electricity or feedstocks; these final demand quantities can be applied too in the analysis.

Table 14 presents the choices, made per method, with respect to primary energy and final demand in end-use sectors. The $O D E X$-indicator is composed of indicators that usually regard one type of energy carrier. In aggregating indicator-results no account is taken of differences between fuels and electricity; therefore primary
Table 14

Applied primary and final demand energy quantities in end-use sectors for various methods

\begin{tabular}{|c|c|c|}
\hline Method & $\begin{array}{l}\text { Primary energy } \\
\text { units }\end{array}$ & $\begin{array}{l}\text { Final energy demand } \\
\text { types }\end{array}$ \\
\hline ODEX-indicator & No & $\begin{array}{l}\text { Fuel and/or } \\
\text { electricity }\end{array}$ \\
\hline Frozen technology & Static & Fuel, electricity \\
\hline Decomposition analysis & No/yes & No \\
\hline PME-decomposition & Static primary & $\begin{array}{l}\text { Heat, electricity, } \\
\text { feedstocks }\end{array}$ \\
\hline Reconstructed balances & $\begin{array}{l}\text { Static/dynamic } \\
\text { primary }\end{array}$ & $\begin{array}{l}\text { Heat, electricity, } \\
\text { feedstocks }\end{array}$ \\
\hline Energy trend simulation & Static primary & Heat, electricity \\
\hline
\end{tabular}

energy is not dealt with. The frozen technology method deals with saving options that usually regard one energy carrier. Here, electricity is generally converted to primary units, using a fixed conversion efficiency value. Decomposition analysis often applies total energy consumption, without taking into account the special features of electricity. According to Ang (1995), sometimes a split is made between fuels and electricity, the contribution of electricity production efficiency to the observed change in energy use is analyzed separately. Even so, this does not provide results for end-users that are based on their primary energy consumption. PMEdecomposition deliberately applies static primary energy units in all energy consumption figures. The method of reconstructed balances uses a combination of static and dynamic primary units (see description in Section 2). The energy trend simulation method expresses energy consumption in primary units, with fixed conversion factors for electricity.

With respect to final demand categories Table 14 shows the following pattern. Energy consumption data, used to construct the $O D E X$-indicator, are corrected for energy consumption of cogeneration systems. Therefore the analysis regards final demand. Frozen technology applies all kind of final demand technologies and implicitly makes a distinction between fuel and electricity. Decomposition analysis generally does not focus on final energy demand, as studies are based on standard energy (consumption) statistics. PME-decomposition, reconstructed balances and energy trend simulation all apply the final demand categories heat and electricity. The first two methods regard feedstocks as final demand category in industry as well.

\subsection{Treatment of uncertainty}

In most evaluation studies there is lack of (reliable) data to disaggregate energy consumption to the lowest aggregation level, and to find appropriate variables to construct reference consumption trends. Therefore it is of importance to know uncertainty margins in results. According to 
Odyssee (2003) no uncertainty margins are calculated for individual energy indicators; the same applies for the aggregated $O D E X$-indicator. Frozen technology regards a very detailed description of energy developments, which makes it cumbersome to calculate uncertainty margins. No results on uncertainty are known for this method. Decomposition analysis has a residual term in the decomposition formula, which sheds light on the quality of the decomposition algorithm. In contrast to attention to improved algorithms in Ang (1995), no attention is given to margins in input data and the combined effect on results. PME-decomposition is the only method that delivers margins in the resulting saving figures. In Gijsen and Boonekamp (2004) margins are specified for all inputs and a Monte-Carlo method is applied to calculate an uncertainty distribution for sectoral and national saving figures. For industry uncertainty margins have been determined at a more detailed level in Neelis et al. (2004). The substantial margins found, e.g. $0.3 \%$-point in total national energy savings of $1.0 \%$ per year, stress the importance of uncertainty analysis. The reconstructed balances method does not calculate margins, but in Boonekamp (2004) qualitative information is given on margins in the calculated 14 contributions to observed change in energy use. For energy trend simulation the same applies as for frozen technology.

\section{Rating of methods as to optimal calculation approach}

The optimal approach is defined here as the method which addresses calculation problems and choices in such a way that detrimental effects on saving results, as described in Section 3, are minimized. The optimality of the six methods presented in this paper is analyzed, using a number of criteria that cover the problems and choices described earlier. Special emphasis has been laid on usefulness of methods for policy evaluation purposes. Therefore, flexibility with respect to aggregation, calculation and presentation is added to these criteria. For the time being practical problems, such as availability of data, are left aside. Results are summarized in Table 15 at the end of this section.

\subsection{Aggregation level}

It is obvious that at national level the change in energyintensity (energy consumption per unit of GDP) does not represent energy savings realized. The reason is that structural changes in the socio-economic system influence energy consumption too. Taking account of these influences is the main reason why each method deals with energy consumption and activity variables at lower aggregation level. Decomposition methods generally use readily available data at a rather high aggregation levels. But at lower levels there probably exist more structural changes that influence reference energy consumption and calculated savings (see Table 7). The example for household (see Table 5) shows that incorporating more structureeffects may deliver substantial higher calculated savings. The same reasoning is conceivable for transport and for non-uniform sectors, such as other metal industry or services. With the exception of uniform energy-intensive processes, it could be said that lower aggregation levels are needed to provide better saving figures. Preference should be given to methods that span the whole range from macro-(national) to micro-(energy technology) level. The frozen technology and energy trend simulation methods meet this requirement most.

\subsection{Appropriate reference variables}

It has been pointed out that methods disaggregate energy consumption up to the level where so-called reference variables exist which are thought to have a close relationship with energy demand. In industry this regards various physical production quantities in the base metal, paper, base chemical and cement production (see Phylipsen et al. (1998)). In other sectors physical variables exist as well, but it is often questionable whether they are fit to calculate the reference consumption. For services the problem of using either floor space or number of employees has been discussed earlier. The earlier given household example highlights that even a set of three or four variables is not enough to construct reference consumption. From these cases it follows that only at a (very) low aggregation

Table 15

Scores of calculation methods on various criteria with respect to optimal calculation of energy savings

\begin{tabular}{|c|c|c|c|c|c|c|c|c|}
\hline & $\begin{array}{l}\text { Aggregation } \\
\text { level }\end{array}$ & $\begin{array}{l}\text { Reference } \\
\text { variables }\end{array}$ & $\begin{array}{l}\text { Reference } \\
\text { technology }\end{array}$ & $\begin{array}{l}\text { Inter-action } \\
\text { savings }\end{array}$ & $\begin{array}{l}\text { Inter-action } \\
\text { growth }\end{array}$ & $\begin{array}{l}\text { Energy } \\
\text { quantity }\end{array}$ & Uncertainty & Flexibility \\
\hline \multicolumn{9}{|l|}{ Methods } \\
\hline Frozen technology & +++ & 0 & ++ & ++ & 0 & ++ & 0 & + \\
\hline Decomposition analysis & + & + & 0 & + & +++ & + & 0 & + \\
\hline PME-decomposition & + & ++ & 0 & ++ & ++ & +++ & +++ & ++ \\
\hline
\end{tabular}

$0=$ none, $+=$ limited, $++=$ fair, $+++=$ complete. 
level it is possible to find appropriate variables to construct reference consumption trends that incorporate all structural factors. Only in very uniform production, e.g. primary aluminium or cement, physical production variables at medium aggregation level can be applied. Again frozen technology and energy trend simulation offer ample opportunities to apply appropriate reference variables.

\subsection{Reference system}

The choice of reference system is relevant only if analysis regards energy using systems, e.g. boilers for space heating or cars for personal travel. In that case the bottom line in the choice of reference system is the 'oldest' type still available in the market. Normally this type is the least energy efficient and the cheapest as well. If this type is not supplied any more, the next best type can be chosen. Calculation of energy savings asks for a vintage approach that, at any moment in time, maps the fractions of more and less efficient types. The changing mix of types and the (changing) reference determine energy savings realized. It is possible to apply more stringent definitions of reference systems as well. For instance, the type with no extra costs to the energy user could be chosen. But this is not a robust choice as investments costs, energy prices or subsidies could change. Another possibility is to define the base year average as reference system; this approach is applied in the Icarus-analysis of saving options in Alsema and Nieuwlaar (2001). However, negative savings may result if total number of systems rises, and implicitly number of efficient types as well, while actual number of efficient systems does not. The method of energy trend simulation, applied to historic household energy consumption in Boonekamp (1997), uses the vintage approach and is flexible as to choice of reference systems.

\subsection{Interaction between (specific) energy-saving effects}

Next to more efficient supply and savings in end-use, energy savings due to cogeneration should be provided, as this issue is a focus points in national and European energy policy. With respect to cogeneration the literature (see overview in Ang (1995)) shows that hardly any decomposition method explicitly looks at energy savings of cogeneration. Generally, this is impossible because total energy consumption is looked at, instead of final energy demand (see Fig. 3). In that case cogeneration savings are part of total end-user savings. In some energy statistics (e.g. Eurostat) cogeneration is made part of the supply sector, and cogeneration savings are concealed in total energy savings of the supply sector. With respect to efficiency in supply, average conversion efficiency of central electricity production is the most important subject. Methods should separately show the saving-effect, due to efficiency changes per type of plant, and the substitution-effect, due to changes in fuel mix. Only few decomposition studies split average efficiency trends into these two factors. Savings on end use are provided by all methods but are mixed up with that of cogeneration often. Overall PME-decomposition and reconstructed balances discern the preferred savings categories best.

As to interactions three types are important:

- between end-use savings on electricity and higher efficiency of power plants,

- between cogeneration and more efficient heat and electricity production,

- for end users, between lowering final demand and more efficient conversion.

The first interaction is important, as policy makers are not only interested in energy savings on its own, but in ultimate effects on total energy consumption and $\mathrm{CO}_{2}$ emissions as well. To take account of this interaction, it is obligatory to discern between fuel and electricity in final energy demand of end users. Moreover, the analysis should be able to analyze the saving-effects for final electricity and that for electricity production in conjunction. This should be possible in standard decomposition analysis, provided enough detail is present. These interaction effects can be highlighted too applying dynamic primary energy consumption in the calculations (see Section 4). For cogeneration savings, not only a trade off with power plant efficiency exists, but one with boiler efficiency as well. Therefore, trends in fuel conversion efficiency of end-users should be available too. Moreover, the quantity primary energy consumption must be applied in the analysis to make cogeneration savings visible. Analysis of the third interaction mentioned requires energy consumption trends for end-users be split into final energy demand and fuel conversion (excluding cogeneration). Given these demands, the reconstructed energy balances method is best suited to take account of all three interactions (compared to other methods designed for analysis at the macro-level, see Table 12). PME-decomposition comes a long way in taking account of the interactions. However, the third type of interaction can be best accounted for at lower aggregation levels where energy technologies are present. The calculation scheme defines how the overlap in saving effects is dealt with. Both frozen technology method and energy trend simulation method are best suited with regard to interaction for end users.

\subsection{Interaction between energy savings and growth factors}

All methods deal with energy savings and the effect of other factors regarding growth of energy consumption, but they do not treat interaction between the two in the same way. The bottom-up methods frozen technology and energy trend simulation calculate savings as the difference between two cases, one using efficiency values for the base year and the other using values for the chosen year. In both cases the same energy trends, based on volume and structural developments, have been composed. This 
approach resembles the partial or Laspeyres-like decomposition where the sum of savings-, structure- and volumeeffects can diverge from total observed change in energy consumption, due to interaction between the effects. The reconstructed balances and PME-decomposition methods also apply partial decomposition, as they calculate one effect after another. Various 'complete' decomposition algorithms (see Ang (1995)) that minimize the interactioneffects are applied in decomposition analysis, being the optimal method with respect to properly accounting for this kind of interaction.

\subsection{Energy quantity applied}

Total energy consumption is the worst quantity to be applied in the construction of reference energy trends and calculation of savings. In contrast to final demand it often has no well-defined relationship with socio-economic trends (see Table 10). Moreover, substitution between electricity and fuels may show up as energy savings in the results. Further on, energy consumption does not give a sound picture of the ultimate burden, especially for the electricity part in it. The alternative quantity 'final energy demand', split into electricity, heat and feedstocks, takes account of quite different growth factors for each type of final demand. The quantity 'primary energy consumption' shows real energetic effects on the total energy system. Moreover, this quantity is needed to reveal the savings of cogeneration. The best solution will be a combination of both quantities, i.e. 'final demand of heat, electricity and feedstocks, expressed in primary energy units'. This approach has been applied in the PME-decomposition method. In reconstructed balances static as well as dynamic primary energy consumption figures are part of the analysis.

\subsection{Reporting uncertainty}

In conformity with standard scientific practice, uncertainty margins should be given for every saving figure presented. Preferably, sources of uncertainty should be made clear too. Bottom-up methods demand much effort to specify margins for the numerous input data and to calculate the uncertainty in saving results. Top-down methods ask fewer inputs but here it is often difficult to estimate the uncertainty in reference energy consumption. This uncertainty depends on how good the variables, used to construct reference consumption, act as 'predictor' of energy consumption in case of absent saving activities. As mentioned earlier, the only method that quantifies uncertainty is $P M E$-decomposition.

\subsection{Flexibility as to policy evaluations demands}

In practice flexibility in the set up of calculation and presentation is important because of the changing availability of data and because of changing needs of policy makers. Even so, most methods cannot supply information in a new preferred policy format, e.g. sheltered versus exposed sectors, or specific energy applications that are subject to policy measures (e.g. co-generation or new dwellings). Some methods are not flexible because of the information sources used. For other methods the calculation scheme has to be adapted for new policy questions. The ODEX-indicator method, being an aggregate of indicators to be chosen at one's discretion, proves to be the most flexible method.

\subsection{Overall scores of methods}

Table 15 presents an overview of the relative ratings for each method, based on the preceding analysis. The results show that none of the methods presented provides high scores on all criteria. The energy trend simulation method has non-zero scores on all criteria.

\subsection{Top-down and bottom-up evaluation for EU-directive}

The emerging Energy Service Directive (ESD, see EC (2005)) specifies targets for energy savings to be realized in EU-countries in the period 2006-2012. The attainment of the saving target for each country will be checked in two ways. Total energy savings achieved are calculated using a top-down decomposition method, in this case the ODEXindicator. Part of total energy savings has to be 'proved', using bottom-up evaluations for policy measures and programmes aimed at specific energy applications or sectors. In Fig. 4 total energy savings have been split into three categories. The ESD-target regards energy savings owing to specific policy measures (e.g. subsidies on saving options) or general measures (e.g. an energy tax). The ODEX-indicator covers all three categories, but does not provide separate information on saving effects of various policy measures and programmes.

The two bottom-up methods presented here, frozen technology and energy trends simulation, supply results at the detailed level of specific policy measures. The latter method can provide saving effects of general policy measures as well (for households in the Netherlands, see Boonekamp (2005)). The simulation method can deal with interaction between these policy measures and energy prices that cause (autonomous) energy savings. Given these results, it is expected that the energy trend simulation method can meet the ESD evaluation needs.

\section{Conclusions and observations}

In past decades much work has been done on developing methods to quantify realized energy savings at national or sectoral level. Even so, the following calculation issues got too little attention so far:

- appropriate aggregation level for analysing energy savings, 


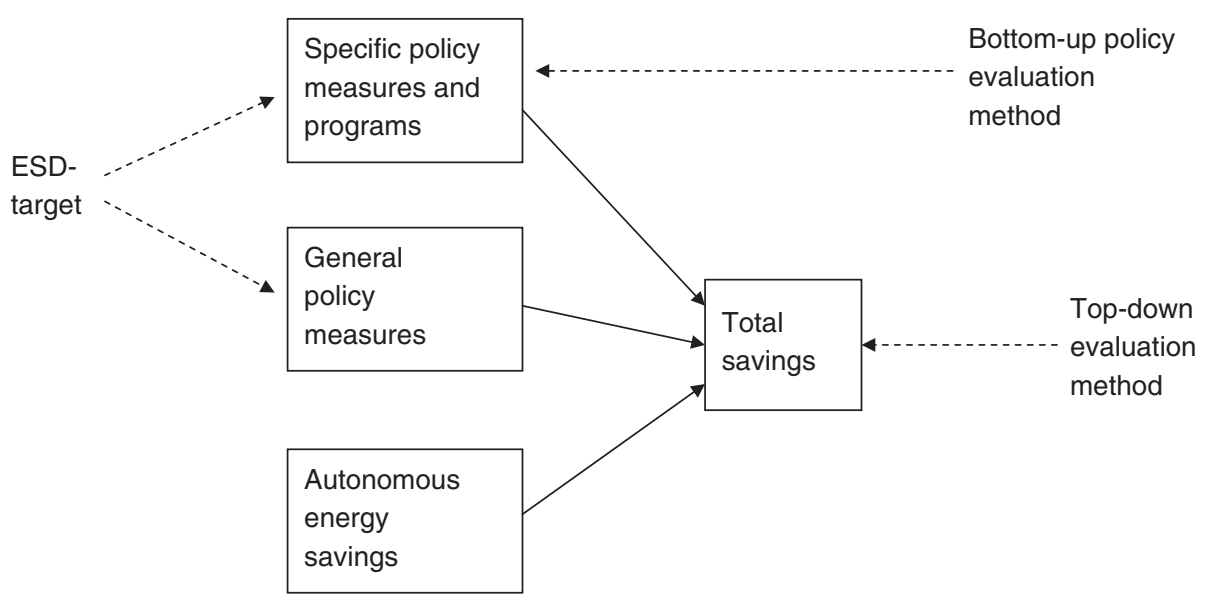

Fig. 4. Energy-saving categories valid for evaluation methods and ESD-target.

- most suitable variables to construct reference consumption,

- appropriate energy quantities to be applied in the analysis,

- interaction between energy-saving effects and other factors,

- uncertainty margins in the results.

The first four issues could lead to unreliable saving figures or misinterpretations of results presented. Then it is the more surprising that hardly any publication in this field provides information on uncertainty margins in results.

Although the calculation methods regarded differ in scope and approach, they all try to answer the same question: what would energy consumption have been without energy-saving activities? This boils down to the problem of constructing a reference consumption trend that, compared with actual energy consumption, shows energy savings. The analysis presented in this paper shows that there is not one method that addresses all calculation issues. But the analysis also suggests a number of improvements, which provide more reliable, transparent and policy relevant saving figures.

\subsection{Energy quantities to be applied}

Instead of the frequently applied quantity 'energy consumption' the quantity 'final energy demand, expressed in primary units' should be applied. Final energy demand has a clear relationship with specific energy using activities. Split into heat and electricity (and feedstocks in some industrial sectors as well), it facilitates construction of more reliable reference consumption trends. Expressing energy consumption in primary units shows the ultimate burden on energy supply and environment. Both items are most important for electricity use, because of the difference in end-use quality for fuels and electricity, and because of the substantial losses in electricity production. The proposed approach enables calculation of energy savings owing to cogeneration at end-users site as well. The methods PME- decomposition and reconstructed balances (MONIT) apply this approach. From a policy perspective the application of static primary units (calculated with base year conversion factors) is useful in presenting energy trends of end-use sectors including their saving performance. Dynamic primary units are needed to present the ultimate effect on energy system and environment, including changes in energy supply. In the method reconstructed balances both results for quantities are presented.

\subsection{Aggregation level and choice of reference variables}

Analysis of energy consumption trends at lower aggregation levels provides for better saving figures. The first reason is that each part of energy consumption can be related to the most suitable reference variable (driving factor) when constructing reference trends. The second reason is that a greater part of structural changes in the socio-economic system can be taken hold of at lower aggregation level. Preferably, bottom-up analysis should be applied, where the aggregation level regards energy systems and saving options. At this level calculated energy savings are not mixed up with structure effects. The demand on data availability seems often prohibitive. However, statistical information in combination with survey results may provide good results, as the simulation method for households, presented here, shows.

\subsection{Interaction to be dealt with}

In decomposition analysis the change in total energy consumption is decomposed into a volume-effect (GDPgrowth), structure effects and energy-saving effects. These effects do not add up to total change, due to interaction between the various effects. Advanced decomposition methods can minimize the difference. However, they generally do not deal with policy relevant interactions, such as between cogeneration savings and power plant efficiency, and between two saving options in end-use sectors. In the reconstructed energy balances method (MONIT) 
cogeneration is defined as a separate saving category, and cogeneration savings can be calculated, including interaction effects. In bottom-up methods, such as energy trend simulation, interaction between saving options in end-use sectors can be analyzed in detail.

\subsection{Uncertainty in results}

Most methods have to rely on a restricted set of, often unreliable, data at a too high aggregation level. Given these shortcomings, uncertainty analysis should be standard in calculating energy savings, but generally lacks in practice. The PME-decomposition method calculates uncertainty margins in savings results, attributing margins to every input and to the constructed reference energy consumption, and applying a Monte-Carlo approach. The margin in national energy savings proves to be about $30 \%$; the most important contribution to uncertainty proves to be application of inappropriate variables in constructing reference energy trends. Analysing at a lower aggregation level can partly lift this problem.

\subsection{EU-directive demands}

Most methods on calculating total savings cannot meet all evaluation needs of the new EU-directive on energy saving, for instance realized savings owing to policy measures. This could be accomplished though, using a method which supplies detailed information on implemented saving options, as well as the part of savings due to policy measures. The bottom-up energy trend simulation method presented here is thought to supply the information needed.

\section{Acknowledgement}

The findings have been based on work, executed at ECN, which was partially funded by the Policy Studies unit. Many thanks go to Prof. Dr. W.C. Turkenburg for his valuable comments on a first version of this paper and to the unknown referee for the stimulating comments.

\section{References}

Alsema, E.A., Nieuwlaar, E., 2001. ICARUS-4 - A database of energy efficiency measures for the Netherlands 1995-2020, report NW\&S-E2001-21, NW\&S, Utrecht University.

Ang, B.W., 1995. Decomposition methodology in industrial energy demand analysis. Energy 20 (11), 1081-1095.

Blasnik, M., 1995. The need for statistical analysis and reporting requirements: some suggestions for regression models. Paper for Energy Program Evaluation Conference, Chicago, August 1995.

Blok, K. et al., 2001. Economic evaluation of sectoral emission reduction objectives for climate change; comparison of 'top-down' and "bottomup' analysis of emission reduction opportunities for $\mathrm{CO}_{2}$ in the EU', Memorandum for DG ENV, NW\&S, Utrecht University.

Boonekamp, P.G.M., 1997. Monitoring the energy use of households using a simulation model. Energy Policy (special issue) 25 (7-9).
Boonekamp, P.G.M., 2004. Energy and emission monitoring for policy use; trend analysis with reconstructed energy balances. Energy Policy 32, 969-988.

Boonekamp, P.G.M., Gijsen, A., Vreuls, H., 2004. Realised energy savings 1995-2002 - according to the protocol on monitoring of energy savings', ECN-C-04-085. ECN, Petten.

Boonekamp, P.G.M., 2005. Price elasticities, policy measures and actual development in household energy consumption - a bottom up analysis for the Netherlands. Energy Economics, to be published.

Bowie, R., Malvik, H.V., 2005. Measuring savings target fulfilment in the proposed directive on energy end-use efficiency and energy services (COM(2003)0739: developing a framework for a harmonised measurement scheme for energy efficiency improvements in the EU'. In: Proceedings ECEEE Summer Study 2005.

Doblin, C.P., 1998. Declining energy intensity in the US manufacturing sector. The Energy Journal 9 (2).

EC, 2005. Directive of EP and EC on Energy End-Use Efficiency and Energy Services. ENER89 CODEC 467. COD, Brussels.

EnergieNed, 1995. Results MAP Energy Distribution Sector 1995 (in Dutch). EnergieNed, Arnhem.

Farla, J., Blok, K., 1997. Monitoring of sectoral energy efficiency improvements in the Netherlands 1980-1994. Report No. 97024, NW\&S, Utrecht University.

Fisher-Vanden, K., et al., 2002. What is driving China's decline in energy intensity? Resource and Energy Economics 26 (1).

Gijsen, A., Boonekamp, P.G.M., 2004. Uncertainty in energy saving figures-background report to "realised energy savings 1995-2002" (in Dutch)', Report 773001030/2004, RIVM, Bilthoven.

Groot, W., 1996. Energy Savings 1990-1994; The Target for 2000 Half Way Out of Sight? (in Dutch). Note 96/IV/15. CPB, Den Haag.

Hoen, A., Mulder, M., 2003. Explaining Dutch emissions of $\mathrm{CO}_{2}$; a decomposition analysis CPB discussion paper no. 24, CPB, Den Haag.

Howarth, R.B., Schipper, L., 1991. Manufacturing energy use in eight OECD countries: trends through 1988. The Energy Journal 12 (4).

IEA, 2004. 30 years of energy use in IEA countries - oil crisis \& Climate challenges. IEA-OECD.

Lapillonne, B., Pollier, K., Bosseboeuf, D., 2004. SAVE-ODYSSEE Monitoring tools for energy efficiency in Europe - energy efficiency index ODEX. Presentation at the ESD expert workshop, Brussels, September 2004, see website ECEEE.

MURE, 2003. MURE; Mesures d'Utilisation Rationelle de l'Energie; Part 2: Back-casting. FhG-ISI, ISIS, Enerdata and ADEME.

Neelis, M., Ramirez, A., Patel, M., 2004. Physical indicators as a basis for estimating energy efficiency developments in the Dutch industry. Report. NWS-E-2004-20, Copernicus Institute/NW\&S, Utrecht University.

Odyssee, 2003. MURE-Odyssee News-Newsletter of the MURE and Odyssee databases. FhG-ISI, ISIS, Enerdata and ADEME.

Phylipsen, G.J.M., Blok, K., Worrell, E., 1998. Handbook on international comparisons of energy efficiency in the manufacturing industry. Report no. 98022, NW\&S, Utrecht University.

RK, 2003. Effectiveness of energy efficiency policy in the greenhouse sector (in Dutch). Algemene Rekenkamer, TK-28780. SDU, Den Haag.

Schipper, L., Murtishaw, S., Unander, F., Ting, M., 2001. Indicators of energy use and carbon emissions: explaining the energy economy link. Annual Review of Energy \& Environment 26, 49-81.

Seibel, S., 2003. Decomposition analysis of $\mathrm{CO}_{2}$-emission changes in Germany-conceptual framework and empirical results. FSO, Germany.

Sun, J.W., 1999. Decomposition of aggregate $\mathrm{CO}_{2}$ emissions in the OECD, 1960-1995. The Energy Journal 20 (3), 147-155.

Zarnikau, J., 1999. Defining 'total energy use' in economic studies: does the aggregation approach matter? Energy Economics 21 (5), $485-492$. 